\title{
Modelo Integrado de Burnout entre Policiais do Distrito Federal: uma Ampliação Conceitual
}

\author{
Paula Soares Lira ${ }^{1}$, Amalia Raquel Pérez-Nebra ${ }^{2}$, Fabiana Queiroga $^{3}$
}

\author{
${ }^{1}$ http://orcid.org/0000-0001-8806-3847/ Centro Universitário de Brasília (UniCEUB), Brasil \\ ${ }^{2}$ http://orcid.org/0000-0001-8386-1233 / Universidade de Brasília (UnB), Brasil; Universidad Internacional de Valencia (VIU), Espanha \\ ${ }^{3}$ http://orcid.org/0000-0002-3811-8202 / Université Côte D’Azur, França
}

Apurar infrações penais por meio da investigação policial está entre as atribuições da Polícia Civil. A extensa carga horária de trabalho e avanço da violência leva os policiais a se exporem ao risco de adoecimento por burnout. Este estudo tem por objetivo testar um modelo integrado em que o burnout será predito pelas demandas e pelos recursos no trabalho. Os instrumentos foram aplicados on-line, distribuídos através da intranet da polícia. Participaram 164 policiais, 56,4\% homens, média de 40,90 anos $(D P=8,22)$ e tempo de exercício de 12 anos $(D P=7,87)$. O modelo empírico foi testado com mediação dupla do estresse percebido (ajustamento pessoa-organização) e experiências restauradoras. As características da tarefa e sociais predizem negativamente o burnout e, portanto, são variáveis protetivas. O ajuste pessoa-organização e restauro são mediadores protetivos desta relação. Os resultados contribuem para a ampliação da literatura a respeito do processo de saúde-doença de profissionais relacionados à segurança pública.

Palavras-chave: estresse ocupacional, polícia, desenho do trabalho, burnout.

\section{Burnout Integrated Model Among Police in the Federal District: a Conceptual Expansion}

\section{Modelo Integrado de Burnout entre Policías del Distrito Federal: una Ampliación Conceptual}

\section{Abstract}

Identifying criminal infractions through police investigation is among the attributions of the Civil Police. The extensive workload and the advancement of violence expose police officers to the risk of becoming ill due to burnout. The present study aims to test an integrated model in which burnout will be predicted by the demands and resources of the work. The instruments were applied online and distributed in the police intranet. One hundred and sixty-four police officers participated, $56.4 \%$ men, with an average age of 40.90 years $(S D=8.22)$ and 12 years of work experience $(S D=7.87)$. The empirical model was tested with dual mediation of perceived stress (person-organisation adjustment) and recovery experiences. Task and social characteristics negatively predict burnout and are therefore protective variables. Personorganization adjustment and recovery are protective mediators of these relationships. The results contribute to expanding the literature about the health-disease process of professionals related to public security.

Keywords: occupational stress, police, work design, burnout.

\section{Resumen}

Investigar las infracciones penales por medio de investigación policial está entre las atribuciones de la Policía Civil. La sobre carga de trabajo y el avance de la violencia exponen a los policías al riesgo de enfermarse de síndrome de burnout. Esta investigación tiene como objetivo probar un modelo integrado en el que el síndrome de burnout será predicho por las demandas y por los recursos en el trabajo. Los instrumentos se aplicaron on-line distribuidos en la intranet de la policía. Participaron 164 policías, $56,4 \%$ hombres, media de edad de 40,90 años $(D T=8,22)$ y tiempo de profesión de 12 años $(D T=7,87)$. El modelo empírico se puso a prueba con doble mediación del estrés percibido (ajuste persona-organización) y las experiencias de recuperación. Las características sociales y de la tarea predicen negativamente el síndrome de burnout y, por tanto, son variables protectoras. El ajuste persona-organización y la restauración son mediadores protectores de esta relación. Los resultados contribuyen para ampliar la literatura sobre el proceso salud/enfermedad de los profesionales relacionados con la seguridad pública.

Palabras clave: estrés ocupacional, policía, diseño del trabajo, síndrome de burnout. 
A polícia civil é um órgão de segurança pública, cuja função é apurar as infrações penais e os respectivos autores por meio da investigação policial. Procedimento administrativo com característica inquisitiva, a investigação policial serve de base ao inquérito policial, previsto no Código de Processo Penal Brasileiro. O inquérito policial é conduzido de forma independente pela polícia civil que o remete ao juízo criminal competente após a sua conclusão (L. P. D. Silva, 2012). Para executar este trabalho os policiais têm uma extensa carga horária de trabalho que, combinada com o avanço da violência, obriga-os a executar o trabalho de forma intensa, desumanizada e com baixa realização no trabalho, expondo-os ao risco de adoecimento no trabalho por burnout (Queirós et al., 2020; C. C. S. Silva et al., 2018). O burnout é a forma de adoecimento mais comum entre trabalhadores expostos a situações de tensão prolongada (Schaufeli, 2017) e é tema de interesse de pesquisadores que analisam diferentes categorias profissionais (ver Editorial de Maslach \& Leiter, 2015).

Burnout e estresse ocupacional são ambas respostas adversas aos estressores do trabalho, contudo, com diferentes antecedentes, correlatos e consequentes (Chirico, 2016; Hyeda \& Handar, 2011; Maslach \& Schaufeli, 1993; Maslach, Jackson, Leiter, Schaufeli, \& Schwab, 1986; Pines \& Keinan, 2005). Ambos causam prejuízos ao trabalhador no exercício das suas atividades laborais e que, consequentemente, acarreta também em impactos negativos para a organização (De Francisco, Arce, Vílchez, \& Vales, 2016). Uma primeira diferenciação entre ambos os constructos se refere à noção de temporalidade. O estresse ocupacional é um termo genérico relacionado à adaptação temporária no trabalho, acompanhada de sintomas mentais e físicos, enquanto o burnout é considerado um mau funcionamento crônico resultante de estresse ocupacional prolongado. O burnout também inclui o desenvolvimento de atitudes e comportamentos disfuncionais em relação aos colegas, ao trabalho e à organização. Contudo, além de ser definido como resposta específica à exposição prolongada ao trabalho, a clássica definição de Maslach (1982) assume que o burnouté uma síndrome psicológica que inclui três componentes: a exaustão, a despersonalização e a redução da percepção de autoeficácia. A exaustão indica a sensação de estar em excesso e esgotado de recursos emocionais e físicos; despersonalização (ou cinismo) refere-se à indiferença ou atitudes distantes em relação aos clientes do serviço (ou ao trabalho em geral); a redução da autoeficácia (ou realização pessoal) refere-se a um sentimento de incompetência ou falta de realização e produtividade no trabalho (Maslach, Schaufeli, \& Leiter, 2001).

Essa definição vem sendo amplamente utilizada e aplicada nas pesquisas sobre burnout e o Maslach Burnout Inventory, desenvolvido no início de 1980 por Maslach et al. (1986), é a medida mais popularmente utilizada (Halbesleben \& Demerouti, 2005). Contudo, Demerouti, Bakker, Vardakou, \& Kantas (2003) argumentam que, do ponto de vista psicométrico, a MBI-GS (versão do instrumento publicada em 1996 para todas as profissões) apresenta uma série de falhas, tal como o possível enviesamento das respostas, já que as questões são apresentadas no sentido negativo para as dimensões exaustão e cinismo e, no sentido positivo, para a dimensão eficácia no trabalho. Outra falha apontada pelos autores refere-se à dimensão exaustão, que mensura somente aspectos afetivos, ignorando aspectos físicos e cognitivos do trabalho.

Assim, com a intenção de superar essas críticas, Evangelia Demerouti propôs em 1999 um instrumento alternativo para mensurar a síndrome de Burnout, o Oldenburg Burnout Inventory (OLBI). O inventário é formado por dois fatores: exaustão e desengajamento do trabalho (disengagement do original, traduzido por Schuster e Dias, 2018, como desligamento no trabalho), e que também pode ser aplicado em qualquer contexto ocupacional, isto é, seus itens refletem a conceituação de burnout sem restrição às profissões. A exaustão, fica sendo entendida como uma consequência da intensa pressão, afetiva e física, ou seja, é uma consequência de longo prazo a exigências consideradas como desfavoráveis de trabalho. O desengajamento do trabalho se caracteriza como se distanciar do objeto e conteúdo do trabalho, particularmente com respeito à identificação com o trabalho e a vontade de continuar na mesma profissão ou organização.

Geralmente os sintomas apresentados por profissionais com síndrome de burnout são de cunho emocional como sentimentos de solidão, impotência, ansiedade, hostilidade, agressividade, apatia, mudanças bruscas de humor, irritabilidade, assim como problemas somáticos. Em termos profissionais e organizacionais registram-se problemas como aumento de risco de erros ou acidentes, diminuição na satisfação, absenteísmo, aumento nos conflitos interpessoais e uma redução na qualidade de vida desse trabalhador (Hyeda \& Handar, 2011; Vazquez et al., 2019).

A alta prevalência do burnout em diversas categorias profissionais levou a síndrome a ser oficializada pela Organização Mundial da Saúde (OMS) como uma síndrome crônica ligada ao trabalho. O burnout deve entrar na Classificação Internacional de Doenças (CID) em 2022 (Organização Mundial da Saúde, 2019). Pesquisas feitas com policiais na África do Sul (Pienaar \& Rothmann, 2006), Canadá (Loo, 1994), França (Michinov, 2005) e Portugal (Luís, 2011) demonstram a existência de altos níveis de adoecimento.

O presente estudo tem como o objetivo analisar os antecedentes do burnout entre policiais civis testando conceitualmente o Modelo Integrado de Burnout (Tamayo, Mendonça, \& Silva, 2012). O modelo será descrito detalhadamente adiante, mas, em síntese, a proposta é que as demandas e recursos no trabalho vão predizer o burnout mediado sequencialmente, pelo estresse ocupacional e as estratégias de enfrentamento utilizadas para o estresse. No contexto brasileiro, pesquisas com policiais civis mostram que o burnout também está cada vez mais presente e frequente. Ainda que estudos descrevam alta realização no trabalho (Ascari et al., 2016), em geral os policiais apresentam sintomas de burnout como sentimentos negativos com relação ao trabalho ou menor sensibilidade (Menegali, Camargo, Rogerio, Carvalho, \& Magajewski, 2010; C. C. S. Silva et al., 2018), e está relacionada a fatores organizacionais como o tipo de tarefa realizada (Silveira et al., 2005). As características do trabalho, isto é, a forma como as demandas e os recursos da sua tarefa são percebidos pelo trabalhador, apresentam diferentes repercussões para a sua atividade laboral (Morgeson \& Humphrey, 2006), entre elas, o burnout.

\section{Demanda-Recurso: Desenho do trabalho}

O desenho no trabalho descreve como as características do trabalho, a criação, a modificação da composição, execução, conteúdo, estrutura das tarefas e papéis, bem como, os impactos que esses fatores refletem no indivíduo e no grupo e nos resultados da organização (Borges-Andrade, Peixoto, Queiroga, \& Pérez-Nebra, 2019; Parker, Morgeson, \& Johns, 2017). Fruto de um processo sócio-histórico, as características do trabalho modificam-se ao longo dos anos, assim como a intensidade com que elas são percebidas pelos trabalhadores.

O desenho do trabalho inclui características que podem ter efeito sobre variáveis de comportamento organizacional, como engajamento e estresse, por exemplo (Parker et al., 2017). Para organizar essas características, Morgeson e Humphrey (2006) propuseram uma taxonomia de desenho do trabalho e medidas específicas para suas categorias e subcategorias. No modelo taxonômico, o desenho do trabalho é composto por quatro categorias (tarefa, conhecimento, social e contextual), inspiradas majoritariamente 
nas teorias motivacionais, divididas em várias subcategorias, conforme é sintetizado na Figura 1 a seguir. cional, encontra resultados favoráveis para a natureza e os valores do trabalho. Em ambos os casos ele faz menção ao ajuste do tra-

Taxonomia de Morgeson e Humprhey (2006) para as características do trabalho

Características da Tarefa
Autonomia na organização do
trabalho
Autonomia na tomada de decisões
Autonomia nos métodos de trabalho
Variedade de tarefas
Significado da tarefa
Identificação da tarefa
Feedback do trabalho
7 subcategorias

\begin{tabular}{|c|}
\hline $\begin{array}{l}\text { Características do } \\
\text { Conhecimento }\end{array}$ \\
\hline $\begin{array}{l}\text { Complexidade do trabalho } \\
\text { Processamento de } \\
\text { informação } \\
\text { Solução de problemas } \\
\text { Variedade de habilidades } \\
\text { Especialização }\end{array}$ \\
\hline 5 subcategorias \\
\hline
\end{tabular}

Características Sociais
Suporte Social
Interdependência iniciada
Interdependência recebida
Interação fora da organização
Feedback dos outros
5 subcategorias

\begin{tabular}{|c|}
\hline $\begin{array}{c}\text { Características do } \\
\text { Contexto }\end{array}$ \\
\hline Conforto no trabalho \\
Demandas físicas \\
Condições de trabalho \\
Uso de equipamentos \\
4 subcategorias
\end{tabular}

Figura 1. Taxonomia de Morgeson e Humprhey (2006) para as características do trabalho

Em um amplo estudo conduzido com policiais militares, Minayo, Souza, e Constantino (2008) encontraram resultados promissores das características sociais e da tarefa para explicar o trabalho dos policiais cariocas. As características das tarefas reúnem aspectos positivos: autonomia - liberdade de planejar, decidir e usar diferentes métodos de trabalho; variedade - exigência de várias tarefas; significância da tarefa - a influência sobre a vida de várias pessoas; identificação da tarefa - o quanto o indivíduo se identifica com aquilo que está realizando; feedback do trabalhoinformação direta e clara sobre como o indivíduo deve executar a tarefa.

As características sociais preveem relações prazenteiras no trabalho: suporte social - apoio e assistência oferecida por terceiros; interdependência - depender de outras pessoas no trabalho e essas pessoas dependerem do seu trabalho; interação fora da organização - interação e comunicação com indivíduos que não tem vínculo com a organização; feedback de outras pessoas - informações sobre o desempenho do trabalhador vindos de outras pessoas (Borges-Andrade et al., 2019). Tais características, associadas aos resultados encontrados por Minayo et al. (2008), encorajaram a formulação da primeira hipótese a ser testada.

H1. As características da tarefa e sociais serão preditores negativos de burnout no âmbito da polícia civil.

\section{Estresse Ocupacional e o Ajustamento no Trabalho}

A relação entre as características do trabalho e o burnout é frequentemente mediada pela avaliação da situação do trabalho, ou seja, pela percepção de estresse (Chirico, 2016; Tamayo et al., 2012). Além do estresse ocupacional, revelado pelos sintomas mentais e físicos decorrente da adaptação temporária buscada pelo trabalhador, a avaliação da situação de trabalho também pode levar à conclusão sobre o grau de (des)ajustamento que o indivíduo tem no seu trabalho. Esse fenômeno, conhecido na literatura como fit, refere-se à adequação da pessoa ao ambiente e pode ser compreendido como complementar ou suplementar. O ajuste complementar ou Pessoa-Atividade (P-A) se caracteriza pela harmonia das habilidades do indivíduo e as exigências de um trabalho, ou seja, o que falta em um compensa no outro. Já o ajuste suplementar ou Pessoa-Organização (P-O) se caracteriza pela congruência dos valores pessoais dos empregados e a cultura de uma organização (Cable \& DeRue, 2002; Werbel \& Demarie, 2001). Embora esse seja um construto pouco abordado pela literatura brasileira, alguns se aproximam conceitualmente (ver revisão de Appio, Carli, Fernandes, \& Frizon, 2019)

Tamayo (2002), ao estudar os preditores de exaustão emo- balho realizado pelo indivíduo e o custo que isso tem. Ceribeli e Severgnini (2018) estudaram outra variável que tem semelhança conceitual com ajustamento e encontram resultados convergentes ao de Tamayo (2002). Na sua pesquisa eles analisaram a influência que a identificação organizacional exerce sobre a exaustão emocional. Os resultados obtidos mostraram que os indivíduos que se identificam com a organização na qual trabalham adoecem menos. Isso pode se dar, pois, quando indivíduos que trabalham em uma organização cujos valores são alinhados aos seus, não convivem com o possível desgaste oriundo dessa incompatibilidade. Estas pesquisas em conjunto sugerem que um baixo nível de ajustamento é um elemento de sofrimento no trabalho. Portanto, pode-se hipotetizar que:

H2. Quanto menor o ajustamento do indivíduo maior será o burnout percebido.

H3. As características do trabalho vão predizer positivamente o ajustamento.

\section{Coping e Experiências de Restauro}

Além do estresse ocupacional, o fracasso de se estabelecer estratégias de enfrentamento (coping) eficientes aparecem na literatura como um importante mediador do burnout (Chirico, 2016; Tamayo et al., 2012). De acordo com a definição clássica de Lazarus e Folkman (1984) o coping refere-se aos "esforços cognitivos e comportamentais em constante mudança para administrar demandas específicas externas e/ou internas que são avaliadas como impositivas ou que excedem os recursos da pessoa" (p. 141).

Sendo assim, uma das alternativas encontradas pelo sujeito para tentar sair do processo de adoecimento são os processos de restauro que, por sua vez, também já foram propostos como mediadores em modelos com burnout (Kinnunen, Feldt, Siltaloppi, \& Sonnentag, 2011). Embora as estratégias de enfrentamento (coping) e as experiências restauradoras sejam conceitualmente parecidas, não são iguais. Uma linha de explicação é de que o coping poderia ser um preditor de restauro (Sonnentag \& Fritz, 2007), e já foram encontradas correlações entre os constructos (Merino-Tejedor, Hontangas, \& Boada-Grau, 2017). Enquanto coping se refere ao estressor e à forma como os indivíduos lidam com ele, as experiências restauradoras se referem à forma como os indivíduos restauram seus recursos internos. Portanto, o restauro pode ser entendido como oposto ao processo de adoecimento ou como uma tentativa de restauração do sistema adoecido, o que pode refletir em uma diminuição nos indicadores de processos fisiológicos (Sonnentag \& Fritz, 2007).

O restauro é composto por quatro dimensões: o distancia- 
mento psicológico, ou seja, a capacidade que o sujeito tem de se desprender do trabalho principalmente de não se pensar nos problemas deixados; o relaxamento que se refere a momentos de lazer vivenciados de forma positiva pelos indivíduos; o domínio que pode ser compreendido pelo quanto de atividades fora do ambiente de trabalho podem ser desafiadoras ou de aprendizagem, geralmente são os passatempos ou hobbies; por fim, o controle que pode ser entendido como o quanto o sujeito pode decidir a respeito das atividades que vai realizar, tanto no trabalho quanto nos momentos de lazer (Sonnentag \& Fritz, 2007).

Pesquisas relacionadas a estratégias de enfrentamento utilizadas por policiais federais descrevem que resolução de problemas, reinterpretação positiva e autodistração atuam positivamente em resultados organizacionais (Freitas, 2013). Essas estratégias são positivamente relacionadas às experiências de restauro. Sonnentag (2018) em uma extensa revisão, sugere que as estratégias de restauro são protetivas, mas particularmente o distanciamento psicológico, por vezes, apresenta resultados controversos. Outras evidências sugerem que o controle mental pode ser particularmente protetivo de burnout (Manzano-García, Ayala-Calvo, \& Desrumaux, 2021). Não obstante, como os policiais estão submetidos a um estresse prolongado, entende-se que o restauro pode ser um mecanismo aplicável. Assim, apresentam-se as últimas hipóteses deste trabalho:

H4. Quanto mais variadas e maior intensidade das estratégias de restauro o indivíduo utilizar menor será a percepção do burnout.

H5. O burnout será predito por desenho no trabalho com dupla mediação com ajustamento e processos de restauro.

Neste contexto, o objetivo do presente estudo foi analisar os antecedentes do burnout testando conceitualmente o Modelo Integrado de Burnout proposto por Tamayo et al. (2012). Os autores propuseram um modelo em que o burnout é predito pela discrepância entre demanda e recurso, mediado duplamente, tanto pelo estresse percebido, como pelas estratégias de enfrentamento (coping), conforme apresentado na Figura 2.

O modelo geral de Tamayo et al. (2012) orientou as escolhas de operacionalizações realizadas. A demanda-recurso foi acessada pelo desenho no trabalho, mais especificamente as dimensões relacionadas às características da tarefa e características sociais devido aos estudos realizados neste contexto (Minayo et al., 2008). O estresse percebido foi mensurado pelo nível de ajustamento no trabalho. As estratégias de enfrentamento (coping) foram interpretadas como experiências restauradoras, visto que o restauro tem o objetivo de atuar um sistema adoecido, diferente do coping que tem um estressor específico (Sonnentag \& Fritz, 2007). Para testar empiricamente o modelo proposto por Tamayo et al. (2012) e, especificamente as hipóteses deste trabalho, foi realizada uma pesquisa transversal, quantitativa e com o foco em policiais civis do Distrito Federal.

\section{Método}

\section{Participantes}

O critério de inclusão foi ser servidor em pleno exercício da sua atividade. Responderam à pesquisa 164 policiais civis sendo que, 56,4\% foram do sexo masculino. A média de idade da amos- tra foi de 40,9 anos $(D P=8,22)$ e o do tempo de polícia foi de 12,0 anos $(D P=7,87)$. Já em relação ao regime de trabalho, $72,4 \%$ dos respondentes trabalham em escala de plantão e $26,4 \%$ em expediente. Em relação ao cargo, 55,5\% dos respondentes foram agentes de polícia. A respeito da área de formação desses profissionais $42,1 \%$ são formados em direito. Além disso, 48,0\% são naturais do Distrito Federal.

\section{Instrumentos}

Burnout. Foi utilizado o Oldenburg Burnout Inventory - OLBI cuja versão para o contexto brasileiro foi adaptada por Schuster e Dias (2018). O instrumento formulado para refletir a conceituação de burnout sem restrição às profissões. O OLBI contém 16 itens que avaliam as dimensões exaustão (consequência em longo prazo a certas exigências desfavoráveis do trabalho) e desengajamento do trabalho (se refere ao distanciamento do objeto e conteúdo do trabalho). O instrumento foi respondido em escala do tipo likert variando de 1 (discordo plenamente) a 5 (concordo plenamente). Ainda que o instrumento contenha dois fatores, as evidências de validade da adaptação da versão brasileira apontam bons indicadores psicométricos para a versão unifatorial (TLI $=0,93$; CFI $=$ 0,94; RMSEA = 0,07).

Desenho no trabalho. Utilizou-se a versão da escala brasileira Work Design Questionnaire - WDQ (Borges-Andrade et al, 2019). A versão final adaptada para o contexto brasileiro contém 71 itens organizados em quatro categorias que se dividem em 18 subcategorias para descrever as características do desenho do trabalho. Conforme já mencionado anteriormente, para o presente estudo foram utilizadas apenas duas categorias, características da tarefa e características sociais, selecionadas a partir dos resultados encontrados na pesquisa de Minayo et al. (2008). Para não tornar o questionário demasiadamente extenso devido à quantidade de instrumentos necessários para realizar o teste do modelo pretendido, foram selecionados os itens com as maiores cargas fatoriais (acima de 0,80) de cada subcategoria. Assim, as características da tarefa foram avaliadas com 10 itens e características sociais com 11 itens. Para ambas, pelo menos dois itens de cada subcategoria (ver Figura 1) foram selecionados (com exceção de feedback do trabalho que só um item atendeu ao critério de seleção) e todos foram respondidos uma escala de concordância de cinco pontos.

Estresse. Foi mensurado pelo nível de ajustamento no trabalho por meio da escala de percepções subjetivas de fit (Cable \& DeRue, 2002), portanto, maiores níveis implicam em maior ajustamento e menores níveis, em menor ajustamento. $\mathrm{O}$ instrumento contém nove itens que avaliam duas dimensões, ajuste complementar e suplementar. Para o presente estudo, um pré-teste dos itens foi realizada. Eles foram traduzidos e as evidências de validade foram verificadas com uma coleta de dados para 75 trabalhadores da população geral. O estudo de adaptação e evidências de validade demonstrou que a versão adaptada tem bons indicadores psicométricos tanto para a solução de dois fatores (cargas fatoriais elevadas e bem definidas; $\alpha=0,90$ para o fator de ajuste complementar e $\alpha=0,89$ o fator de ajuste suplementar), quanto para a versão unifatorial que indica o ajustamento geral do indivíduo $(\alpha$ $=0,91)$. Todos os itens são respondidos em uma escala de concordância de cinco pontos e no presente estudo foi considerada a

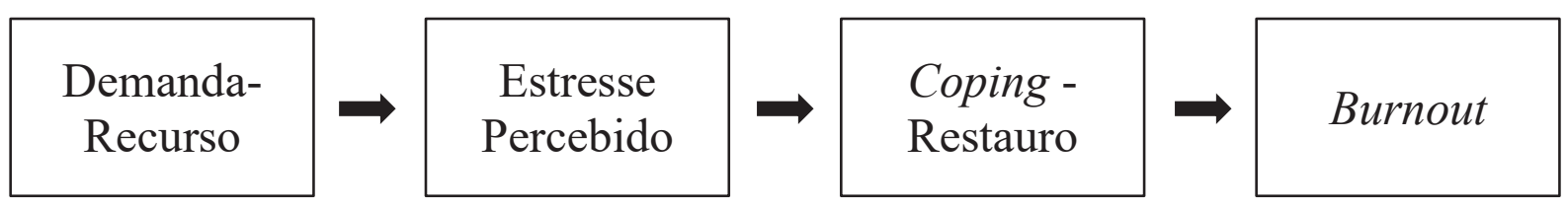

Figura 2. Modelo simplificado de integração do burnout no processo de estresse ocupacional de Tamayo et al. (2012). 
versão unifatorial dessa medida.

Coping. Esse construto foi avaliado por meio da escala de experiências de restauro, a Recovery Experiences - Mastery Experiences (Sonnentag \& Fritz, 2007), em adaptação para o Brasil (Pérez-Nebra et al. 2021). O instrumento é composto por 16 itens que descrevem: distanciamento psicológico $(\alpha=0,84)$; relaxamento $(\alpha$ $=0,91)$; domínio $(\alpha=0,92)$; controle $(\alpha=0,91)$. Todos os itens foram respondidos em uma escala de concordância de 5 pontos.

\section{Procedimentos de Coleta de Dados e Cuidados Éticos}

Depois de acordados os construtos a serem avaliados com a polícia civil do Distrito Federal, firmou-se a parceria e o projeto foi submetido ao comitê de ética (CAAE: 16315919.1.0000.0023). A coleta de dados ocorreu por meio da aplicação de um questionário on-line que foi enviado para o responsável pelo andamento da pesquisa dentro da polícia. Foi atribuição da polícia fazer a divulgação da pesquisa (que foi publicada inclusive no site do sindicato - SinpolDF) e também o envio do link para os respondentes.

\section{Procedimentos de Análise de Dados}

Realizaram-se testes de pressupostos (normalidade e homocedasticidade). Os fatores da escala de WD (características da tarefa e sociais), de ajustamento e de processos de restauro não apresentaram violação aos pressupostos. Já o fator de burnout apresentou assimetria para a esquerda (negativa). Entretanto, decidiu-se pela não correção, pois essas violações não eram tão graves a ponto de necessitar correção ou outra estratégia estatística. Observou-se a confiabilidade dos instrumentos por meio do alfa de Cronbach e as escalas apresentaram bons índices psicométricos. Foi testada a diferença entre os cargos, tempo de trabalho, idade e sexo, entretanto, não apareceram diferenças significativas.

A primeira bateria dos testes de hipótese foi pelas correlações e se eliminou as variáveis com correlações abaixo de $|0,35|$. Os testes de regressão foram realizados na seguinte sequência: regressão de cada variável com burnout, e teste de redução da significância na introdução da variável incluída (cf. Hayes, 2013). O teste do modelo completo foi conduzido apenas para as variáveis que são significativas. A Figura 3 apresenta uma síntese do modelo empírico testado.

Para o teste do efeito de mediação dupla em sequência foi utilizando o Modelo 6 do módulo do Process, versão 3.4, desenvolvido por Hayes (2013) para o SPSS (Statistical Package for Social Science). A interpretação dos efeitos de mediação foi realizada conforme os passos explicitados por Baron e Kenny (1986).

Passo 1. A relação entre a variável preditora (VI) e a variável critério (VD) deve ser significativa;

Passo 2. A variável preditora deve estar relacionada com a variável mediadora;

Passo 3. O mediador deve relacionar-se com a variável critério após o efeito do preditor ter sido controlado;

Passo 4. Deve haver uma redução na força da associação entre as variáveis preditora e critério quando o mediador é considerado no modelo.

\section{Resultados}

Os resultados descritivos sugerem que parte dos respondentes se considera adoecida (média de burnout $=3,73 ; D P=1,00$ ). Com relação aos fatores estressantes, nota-se que o ajustamento do indivíduo no ambiente de trabalho é baixo $(M=2,44 ; D P=$ 1,04). As estratégias de restauro e desenho do trabalho estão próximas ao ponto médio da escala. A média dos fatores com seus respectivos desvios-padrão e as correlações bivariadas entre eles estão apresentadas na Tabela 1 .

De um modo geral obteve-se correlações significativas entre o burnout e as demais variáveis. Com relação à direção da correlação, praticamente todas apresentam sentido negativo. Essa relação inversa nos indica que à medida que aumenta a percepção das variáveis estudadas, diminui a percepção do burnout e, sendo assim, as variáveis selecionadas para o teste do modelo atuam como protetivas desse construto.

Após realizar a inspeção da relação entre as variáveis, prosseguimos com a execução dos passos necessários até o teste do modelo final com mediação dupla. Para analisar o efeito da variável mediadora, é necessário comparar os resultados encontrados nos passos 1 e 3 sugeridos por Baron e Kenny (1986) que também são os passos que permitem testar as hipóteses 1 e 2 da pesquisa. Como destaca a Figura 4, a primeira parte do modelo empírico será testada e descrita na Tabela 2. O passo 2 vem na sequência para testar a Hipótese 3 da pesquisa.

A Tabela 2 sintetiza os testes de regressão em que o nível de ajustamento e as subcategorias de desenho do trabalho foram consideradas separadamente como preditores de burnout (passo 1) e depois em conjunto (passo 3). efeitos sobre estados psicológicos, bem-estar, satisfação e produtividade.

No passo 1 se observou o efeito direto de todas as variáveis realizando-se regressões lineares simples para cada variável com o burnout. No passo 3 foram realizadas regressões lineares múltiplas em que o nível de ajustamento (considerado mediador no modelo geral) foi inserido conjuntamente com as subcategorias de desenho do trabalho. Apesar das variáveis não terem reduzido a significância como se esperava, González-Romá e Hernández (2017) sugerem que é possível testar a mediação. Observa-se que os níveis de significância apresentados pelos fatores relacionados ao desenho do trabalho, de maneira geral, não perdem seu valor preditivo com exceção para significado da tarefa. Embora os de-

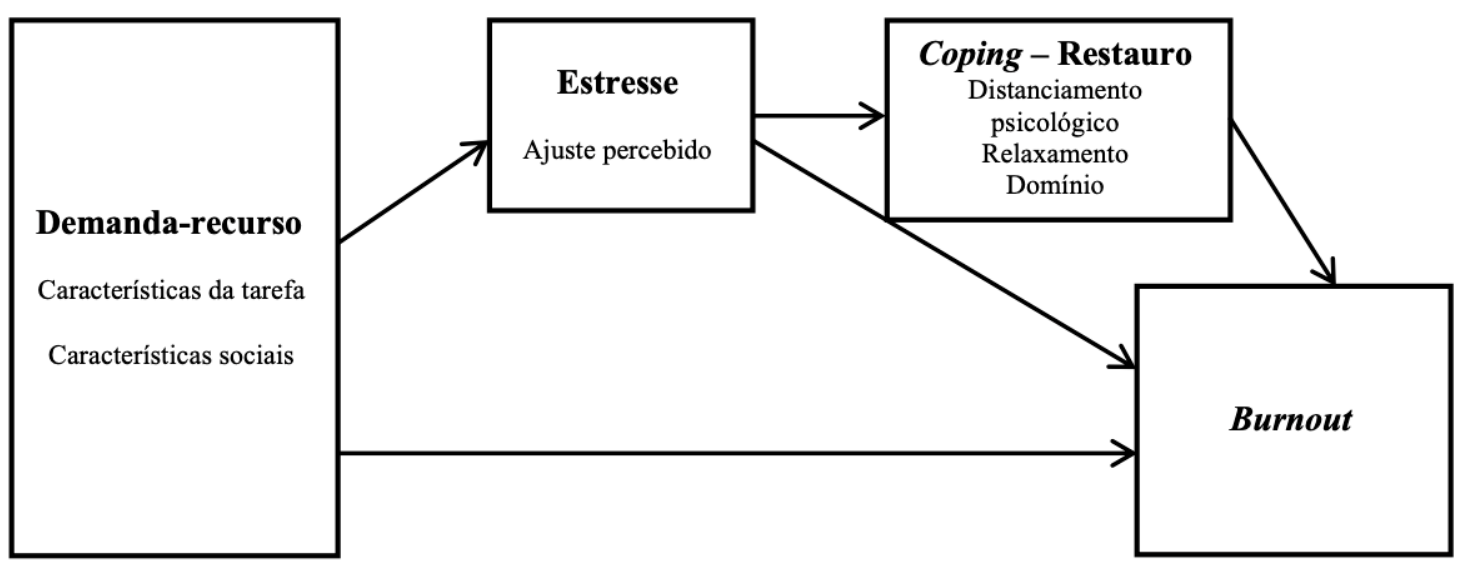

Figura 3. Modelo empírico testado no presente estudo construído a partir do modelo de integração do burnout no processo de estresse ocupacional de Tamayo et al. (2012). 
Correlações de Pearson entre burnout, ajustamento no trabalho, restauro e as subcategorias de desenho do trabalho (características da tarefa e sociais). (Alfas na diagonal).

\begin{tabular}{|c|c|c|c|c|c|c|c|c|c|c|c|c|c|c|c|c|c|}
\hline Variáveis & $\begin{array}{l}\text { Média } \\
(D P)\end{array}$ & 1 & 2 & 3 & 4 & 5 & 6 & 7 & 8 & 9 & 10 & 11 & 12 & 13 & 14 & 15 & 16 \\
\hline $\begin{array}{c}1 \text { Ajustamento no } \\
\text { trabalho }(f i t)\end{array}$ & $2,44(1,04)$ & $(0,93)$ & & & & & & & & & & & & & & & \\
\hline 2 WD: Autonomia & $\begin{array}{r}2,64 \\
(1,25)\end{array}$ & $0,43^{* *}$ & $(0,89)$ & & & & & & & & & & & & & & \\
\hline $\begin{array}{l}3 \text { WD: Tomada } \\
\text { Decisões }\end{array}$ & $\begin{array}{r}2,42 \\
(1,21)\end{array}$ & $0,51^{* *}$ & $0,76^{* *}$ & $(0,90)$ & & & & & & & & & & & & & \\
\hline $\begin{array}{c}4 \text { WD: Variedade } \\
\text { da Tarefa }\end{array}$ & $\begin{array}{r}3,79 \\
(1,26)\end{array}$ & $0,36^{* *}$ & $0,38^{* *}$ & $0,44 * *$ & $(0,91)$ & & & & & & & & & & & & \\
\hline $\begin{array}{c}5 \text { WD: Significado } \\
\text { da Tarefa }\end{array}$ & $\begin{array}{r}3,71 \\
(1,25)\end{array}$ & $0,42^{* *}$ & $0,32^{* *}$ & $0,37^{* *}$ & $0,57^{* *}$ & $(0,81)$ & & & & & & & & & & & \\
\hline $\begin{array}{c}6 \text { WD: } \\
\text { Identificação da } \\
\text { Tarefa }\end{array}$ & $\begin{array}{r}3,04 \\
(1,24)\end{array}$ & $0,44^{* *}$ & $0,36^{* *}$ & $0,40^{* *}$ & $0,33^{* *}$ & $0,49 * *$ & $(0,78)$ & & & & & & & & & & \\
\hline $\begin{array}{c}7 \text { WD: Feedback } \\
\text { do Trabalho }\end{array}$ & $\begin{array}{r}2,44 \\
(1,33)\end{array}$ & $0,49^{* *}$ & $0,41^{* *}$ & $0,51^{* *}$ & $0,28^{* *}$ & $0,40^{* *}$ & $0,57^{* *}$ & - & & & & & & & & & \\
\hline $\begin{array}{l}8 \text { WD: Suporte } \\
\text { Social }\end{array}$ & $\begin{array}{r}3,39 \\
(1,06)\end{array}$ & $0,43^{* *}$ & $0,50^{* *}$ & $0,50^{* *}$ & $0,45^{* *}$ & $0,51^{* *}$ & $0,34^{* *}$ & $0,36^{* *}$ & $(0,80)$ & & & & & & & & \\
\hline $\begin{array}{c}9 \text { WD: } \\
\text { Interdependência }\end{array}$ & $\begin{array}{r}3,28 \\
(1,01)\end{array}$ & $0,15^{*}$ & 0,09 & 0,09 & $0,37^{* *}$ & $0,40^{* *}$ & $0,16^{*}$ & 0,00 & $0,26 * *$ & $(0,75)$ & & & & & & & \\
\hline 10 WD: Interação & $\begin{array}{r}3,23 \\
(1,22)\end{array}$ & $0,25^{* *}$ & $0,19^{*}$ & $0,23^{* *}$ & $0,28^{* *}$ & $0,35^{* *}$ & $0,17^{*}$ & 0,01 & $0,37^{* *}$ & $0,26^{* *}$ & $(0,87)$ & & & & & & \\
\hline $\begin{array}{l}11 \text { WD: Feedback } \\
\text { dos Outros }\end{array}$ & $\begin{array}{r}2,46 \\
(1,20)\end{array}$ & $0,43^{* *}$ & $0,31^{* *}$ & $0,39 * *$ & $0,21 * *$ & $0,28^{* *}$ & $0,26 * *$ & $0,43^{* *}$ & $0,43^{* *}$ & 0,14 & $0,41^{* *}$ & $(0,89)$ & & & & & \\
\hline $\begin{array}{c}12 \mathrm{R}: \\
\text { Distanciamento } \\
\text { psicológico }\end{array}$ & $\begin{array}{r}2,39 \\
(1,03)\end{array}$ & 0,04 & $-0,05$ & 0,00 & $-0,01$ & $-0,04$ & 0,04 & $-0,02$ & 0,06 & $-0,03$ & $-0,09$ & $-0,01$ & $(0,84)$ & & & & \\
\hline 13 R: Relaxamento & $\begin{array}{r}2,57 \\
(1,08)\end{array}$ & $0,26^{* *}$ & $0,20^{* *}$ & $0,23^{* *}$ & $0,19 *$ & $0,33^{* *}$ & $0,26^{* *}$ & $0,21^{* *}$ & $0,37^{* *}$ & 0,09 & 0,12 & $0,20 *$ & $0,46 * *$ & $(0,91)$ & & & \\
\hline 14 R: Domínio & $\begin{array}{r}3,00 \\
(1,20)\end{array}$ & $0,26 * *$ & $0,38^{* *}$ & $0,33 * *$ & $0,31^{* *}$ & $0,34 * *$ & 0,03 & 0,14 & $0,40^{* *}$ & $0,24 * *$ & $0,26 * *$ & $0,27 * *$ & $0,15^{*}$ & $0,50 * *$ & $(0,92)$ & & \\
\hline 15 R: Controle & $\begin{array}{r}2,85 \\
(1,04)\end{array}$ & $0,33^{* *}$ & $0,49^{* *}$ & $0,51^{* *}$ & $0,27^{* *}$ & $0,29 * *$ & $0,27^{* *}$ & $0,25^{* *}$ & $0,36^{* *}$ & 0,14 & 0,14 & $0,23^{* *}$ & $0,27^{* *}$ & $0,58^{* *}$ & $0,55^{* *}$ & $(0,91)$ & \\
\hline 16 Burnout & $\begin{array}{r}3,73 \\
(1,00)\end{array}$ & $-0,57^{* *}$ & $-0,51^{* *}$ & $-0,62 * *$ & $-0,24^{* *}$ & $-0,36^{* *}$ & $-0,42^{* *}$ & $-0,48^{* *}$ & $-0,42^{* *}$ & 0,04 & $-0,18^{*}$ & $-0,04$ & $-0,16^{*}$ & $-0,41 * *$ & $-0,37^{* *}$ & $-0,42^{* *}$ & $(0,94)$ \\
\hline
\end{tabular}

Nota. $* p<0,05 ; * * p<0,01 ; \mathrm{WD}=$ Desenho do Trabalho (Work. Design); $\mathrm{R}=$ Restauro

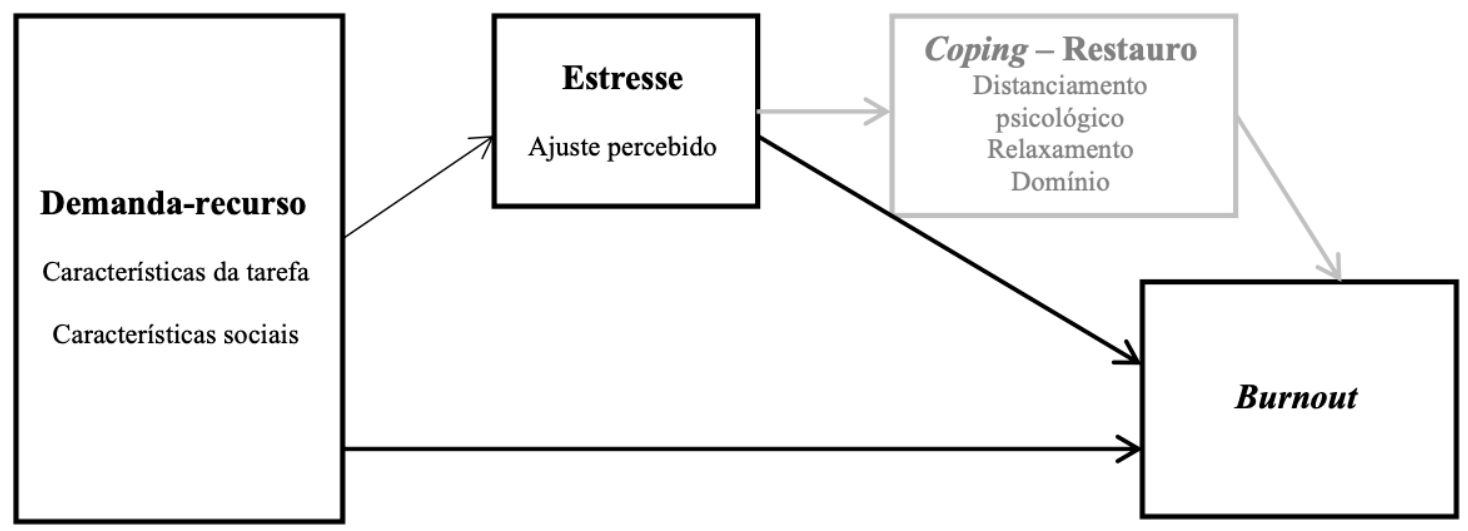

Figura 4. Regressões testadas a partir do modelo empírico da pesquisa para o cumprimento dos passos 1 e 3 sugeridos por Baron e Kenny (1986), considerando o primeiro mediador.

mais mantenham a significância, o beta desse fator é intensamente reduzido.

Os resultados da Tabela 2 oferecem suporte à Hipótese 1 (H1) em que as características da tarefa e características sociais do trabalho são preditores negativos de burnout. Também oferece suporte a Hipótese 2 (H2) e mostra que um ajustamento menor prediz maiores índices de burnout.

De acordo com os passos sugeridos por Baron e Kenny (1986), é necessário ainda checar a relação entre as variáveis preditoras e mediadoras (passo 2). Contudo, no caso do teste do modelo de Tamayo et al (2012), há uma sequência de duas variáveis mediadoras (estresse e coping, mensurados no presente estudo pelo nível de ajustamento e processo de restauro, respectivamente). Por isso, foi necessário testar as subcategorias de desenho do trabalho como preditores do nível de ajustamento conforme destaca a Figura 5.

Assim, procedeu-se as regressões lineares simples, independentes, apresentadas na Tabela 3. Como pode ser observado, todos os fatores de WDQ testados apresentaram betas significativos dando suporte à Hipótese 3 de pesquisa.

Tais resultados também dão apoio para o teste da Hipótese 3 (H3) que propunha a predição de ajustamento pelo desenho do trabalho. Assim, dando continuidade aos procedimentos sugeridos por Baron e Kenny (1986), foram realizados novamente testes de regressão, mas neste momento, as experiências de restauro foram consideradas como preditores de burnout (Figura 6, Tabela 
Tabela 2

Regressão testando ajustamento no trabalho (fit) e subcategorias de desenho do trabalho como preditores de burnout

\begin{tabular}{|c|c|c|c|c|c|}
\hline \multirow[b]{2}{*}{ Variáveis antecedentes } & \multicolumn{2}{|c|}{ Passo 1} & \multicolumn{3}{|c|}{ Passo 3} \\
\hline & $R^{2}$ & Beta & $R^{2}$ & $\begin{array}{l}\text { Beta } \\
\text { WD }\end{array}$ & Beta fit \\
\hline $\begin{array}{l}\text { Ajustamento no trabalho } \\
\text { (fit) }\end{array}$ & $0,33^{* *}$ & $-0,57 * *$ & & & \\
\hline WD: Autonomia & $0,26^{* *}$ & $-0,52^{* *}$ & $0,41 * *$ & $-0,33^{* *}$ & $-0,43^{* *}$ \\
\hline $\begin{array}{l}\text { WD: Tomada de } \\
\text { decisões }\end{array}$ & $0,38^{* *}$ & $-0,62^{* *}$ & $0,47 * *$ & $-0,44 * *$ & $-0,35^{* *}$ \\
\hline $\begin{array}{l}\text { WD: Significado da } \\
\text { tarefa }\end{array}$ & $0,12 * *$ & $-0,36^{* *}$ & $0,34 * *$ & $-0,14 \mathrm{~ns}$ & $-0,52^{* *}$ \\
\hline $\begin{array}{l}\text { WD: Identificação da } \\
\text { tarefa }\end{array}$ & $0,17^{* *}$ & $-0,42^{* *}$ & $0,35^{* *}$ & $-0,21 * *$ & $-0,49^{* *}$ \\
\hline $\begin{array}{l}\text { WD: Feedback do } \\
\text { trabalho }\end{array}$ & $0,23 * *$ & $-0,49 * *$ & $0,38^{* *}$ & $-0,27 * *$ & $-0,45^{* *}$ \\
\hline WD: Suporte social & $0,18^{* *}$ & $-0,43^{* *}$ & $0,36^{* *}$ & $-0,21 * *$ & $-0,48^{* *}$ \\
\hline $\begin{array}{l}\text { WD: Feedback dos } \\
\text { outros }\end{array}$ & $0,16^{* *}$ & $-0,40 * *$ & $0,35^{* *}$ & $-0,19 * *$ & $-0,50^{* *}$ \\
\hline
\end{tabular}

Nota. ${ }^{*} p<0,01 ; \mathrm{WD}=$ Desenho do trabalho (Work Design)

Tabela 3

Regressão testando subcategorias de desenho do trabalho como preditores do nivel de ajustamento

\begin{tabular}{ccc}
\hline Variável antecedente & $\mathrm{R}^{2}$ & Beta \\
\hline WD: Autonomia & $0,19^{* *}$ & $0,44^{* *}$ \\
WD: Tomada de decisão & $0,27^{* *}$ & $0,52^{* *}$ \\
WD: Variedade de tarefa & $0,14^{* *}$ & $0,37^{* *}$ \\
WD: Significado da Tarefa & $0,18^{* *}$ & $0,43^{* *}$ \\
WD: Identificação da Tarefa & $0,20^{* *}$ & $0,45^{* *}$ \\
WD: Feedback do Trabalho & $0,24^{* *}$ & $0,49^{* *}$ \\
WD: Suporte Social & $0,19^{* *}$ & $0,44^{* *}$ \\
WD: Feedback dos Outros & $0,19^{* *}$ & $0,44^{* *}$
\end{tabular}

Nota.** $p<0,01 ; \mathrm{WD}=$ desenho do trabalho (Work. Design)
4). Será possível, com ele testar a Hipótese 4 da pesquisa. Nesse caso, no passo 1 se observou o efeito direto de todas as variáveis e no passo 3 foi controlado o efeito do nível de ajustamento como mediador. O passo 2 vem explicado na sequência.

Observa-se que os processos de restauro também diminuem os betas quando analisado em conjunto com o nível de ajustamento percebido no trabalho e dão suporte à hipótese H4. Entretanto, mesmo diminuindo, continuam significativos. O passo 2 dessa etapa testou a relação entre os mediadores que são colocados em sequência no modelo empírico, conforme destaca a Figura 7.

Nesse caso, foi necessária apenas uma regressão linear simples em que o nível de ajuste percebido foi considerado como variável antecedente e os fatores de restauro foram adotados, separadamente, como variáveis critério. Os resultados são apresentados a seguir na Tabela 5 .

Como pode ser percebido, os resultados foram significativos para os três fatores de restauro. Após a realização dos todos os passos, foi testado o teste do modelo completo. No caso de testes de regressão com mediações duplas em sequência, as regressões são realizadas por partes e são apresentados os efeitos para cada etapa. Contudo, na Tabela 6 são apresentados apenas os efeitos finais, isto é, aqueles em que foram verificados os efeitos de mediação dupla (completa).

As diferentes experiências de restauro são capazes de mediar os efeitos do desenho do trabalho e do ajustamento dando suporte ao modelo geral proposto por Tamayo et al. (2012). A carac-

Tabela 4

Regressão testando ajustamento e processos de restauro como preditores de burnout.

\begin{tabular}{ccccccc}
\hline \multirow{2}{*}{$\begin{array}{c}\text { Variáveis } \\
\text { antecedentes }\end{array}$} & \multicolumn{2}{c}{ Passo 1 } & & \multicolumn{3}{c}{ Passo 3 } \\
\cline { 2 - 3 } \cline { 5 - 7 } & $R^{2}$ & Beta & & $R^{2}$ & $\begin{array}{c}\text { Beta } \\
\text { Restauro }\end{array}$ & Beta fit \\
\hline $\begin{array}{c}\text { Ajustamento } \\
\text { percebido (fit) }\end{array}$ & $0,33^{* *}$ & $-0,57^{* *}$ & & & \\
R: Relaxamento & $0,18^{* *}$ & $-0,42^{* *}$ & & $0,40^{* *}$ & $-0,28^{* *}$ & $-0,50^{* *}$ \\
R: Domínio & $0,14^{* *}$ & $-0,38^{* *}$ & & $0,38^{* *}$ & $-0,24^{* *}$ & $-0,51^{* *}$ \\
R: Autonomia & $0,18^{* *}$ & $-0,43^{* *}$ & & $0,39^{* *}$ & $-0,28^{* *}$ & $-0,49^{* *}$ \\
\hline
\end{tabular}

Nota. ${ }^{*} p<0,01 ; \mathrm{R}=$ Restauro

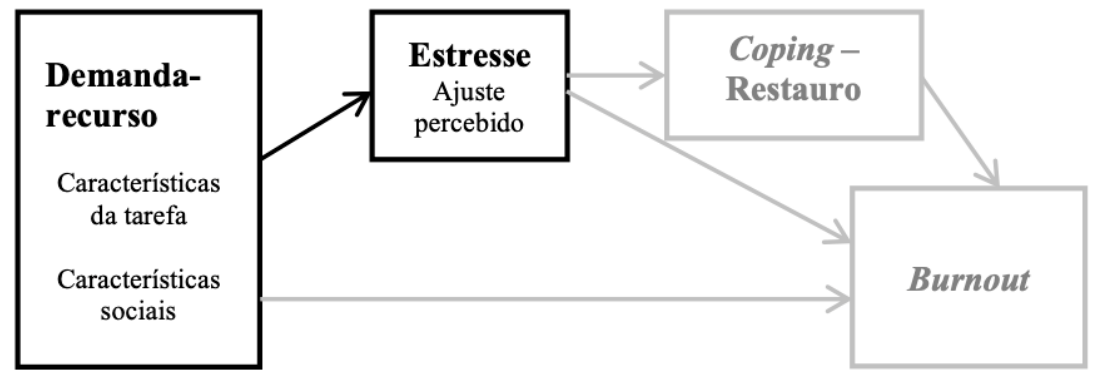

Figura 5. Regressões testadas a partir do modelo empírico da pesquisa para o cumprimento do passo 2 sugerido por Baron e Kenny (1986), considerando o primeiro mediador.

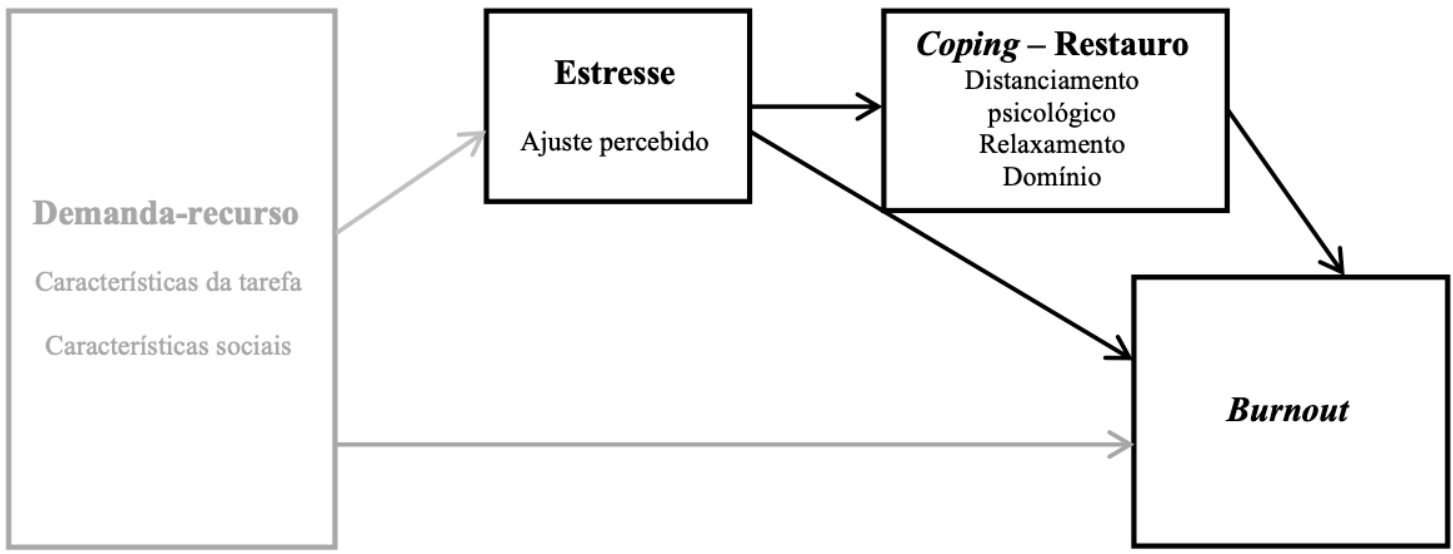

Figura 6. Regressões testadas a partir do modelo empírico da pesquisa para o cumprimento dos passos 1 e 3 sugeridos por Baron e Kenny (1986), considerando o segundo mediador. 


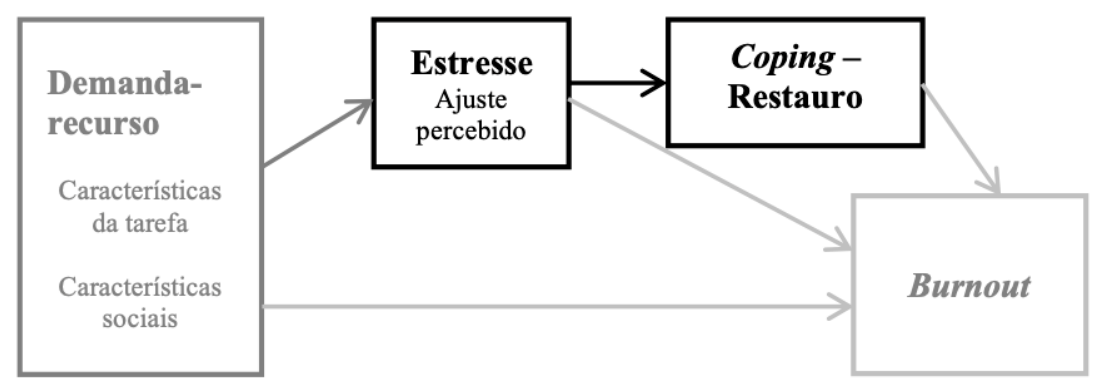

Figura 7. Regressões testadas a partir do modelo empírico da pesquisa para o cumprimento do passo 2 sugerido por Baron e Kenny (1986), considerando o segundo mediador.

Tabela 5

Regressão testando o nível de ajustamento percebido como preditor de processos de restauro

\begin{tabular}{|c|c|c|c|c|c|c|}
\hline \multirow{2}{*}{$\begin{array}{c}\text { Variável } \\
\text { antecedente }\end{array}$} & \multicolumn{2}{|c|}{ R: Relaxamento } & \multicolumn{2}{|c|}{ R: Domínio } & \multicolumn{2}{|c|}{ R:Autonomia } \\
\hline & $R^{2}$ & Beta & $R^{2}$ & Beta & $R^{2}$ & Beta \\
\hline $\begin{array}{c}\text { Ajustamento no } \\
\text { trabalho (fit) }\end{array}$ & $0,08^{* *}$ & $0,27 * *$ & $0,07 * *$ & $0,27 * *$ & $0,12^{* *}$ & $0,34 * *$ \\
\hline
\end{tabular}

terística do trabalho tomada de decisão é a única que não apresenta efeitos mediados entre ajuste e restauro, sua mediação nas análises se dá apenas pelo ajustamento no trabalho. É possível interpretar que a Hipótese 5, onde se considera o modelo geral da pesquisa, apresenta suporte empírico.

\section{Discussão}

Essa pesquisa teve como objetivo testar conceitualmente o modelo de Tamayo et al. (2012) aplicado ao adoecimento dos policiais civis do Distrito Federal. Sugeriu-se que as características sociais e da tarefa seriam preditores de burnout $(\mathrm{H} 1)$ e essa hipótese apresentou suporte empírico. Isso quer dizer que, o indivíduo que perceber essas características no seu trabalho tem maiores recursos que funcionam como protetivos para evitar o adoecimento (Leite, 2007; Minayo et al., 2008). Resultados similares foram encontrados com trabalhadores espanhóis (Hidalgo Jiménez, 2019).

Propôs-se que quanto menor o ajustamento do indivíduo maior seria o nível de burnout apresentado por ele (H2) e essa hipótese também ganhou suporte empírico. Isso quer dizer que, quanto mais ajustado o sujeito está ao seu ambiente de trabalho mais protegido de burnout ele está. A confirmação da hipótese corrobora os estudos já realizados sobre o tema (Ceribeli \& Severgnini, 2018). Da mesma forma, a hipótese de que as características do trabalho (WD) predizem positivamente o ajustamento (H3) também apresentou suporte empírico. Significa dizer que, quando as características do trabalho são motivadoras, tendem a facilitar o ajustamento dos indivíduos no trabalho (Edwards, Cable, Williamson, Lambert, \& Shipp, 2006; Kristof-Brown \& Guay, 2011).

No modelo de Tamayo et al. (2012), o processo de enfrenta- mento do estresse é preditor do burnout. Essa premissa orientou a formulação da quarta hipótese (H4), isto é, a variedade e maior intensidade de experiências de restauro estariam relacionadas à redução do burnout. Os resultados também deram suporte à essa hipótese e, portanto, as experiências de restauro de relaxamento, domínio e autonomia reduzem o burnout. Entretanto, o distanciamento psicológico se mostrou como uma variável pouco protetiva quando comparada às demais. Este resultado corrobora outros achados que encontraram relações mais intensas e protetivas para os processos de restauro como relaxamento e controle (Manzano-García et al., 2021; Sanz-Vergel et al., 2010; Shimazu, Sonnentag, Kubota, \& Kawakami, 2012; Sonnentag \& Fritz, 2007) e relações nulas com distanciamento psicológico (Merino-Tejedor et al., 2017; Sonnentag, 2018).

Vale ressaltar que, embora os processos de restauro tenham o potencial de aliviar os impactos no trabalho, as pesquisas empíricas encontram um processo paradoxal: quanto mais necessário o restauro, menos o indivíduo consegue alcançá-lo (Sonnentag, 2018). Sonnentag (2018) sugere que quando os profissionais encontram altos níveis de estresse, eles tendem a se distanciar menos do trabalho. Ou seja, alto estresse demanda alta intensidade de restauro, mas essa tensão apresenta baixa propensão ao restauro, levando a uma situação que ela chamou de "paradoxo do restauro". Esta tensão paradoxal entre estressores e restauro pode ser explicada por diversos mecanismos psicológicos e é uma pergunta em aberta para futuras pesquisas que vai além do escopo da presente pesquisa.

O teste do modelo completo, onde restauro seria um mediador entre o ajustamento e burnout também apresentou suporte empírico (H5). Este resultado difere ao de Kinnunen et al. (2011), eles encontraram mediação parcial pelas estratégias de restauro entre demandas e burnout. Assim, a pesquisa apresenta contribuições relevantes para o campo de atuação e de investigação. Estas foram: mapear e descrever, a partir do teste do modelo integrado de burnout, quais são os antecedentes do burnout, ou seja, quais fatores podem proteger do processo de adoecimento vivenciado pelos policiais civis.

A partir do modelo teórico testado e de estudos como esse, as

Tabela 6

Teste do modelo completo: desenho do trabalho predizendo burnout com mediação completa por nível de ajustamento percebido no trabalho e de experiências de restauro

\begin{tabular}{|c|c|c|c|c|c|c|c|c|c|}
\hline Variável antecedente & Efeito1 & LLCI & ULCI & Efeito2 & LLCI & ULCI & Efeito3 & LLCI & ULCI \\
\hline WD: Autonomia & $-0,02 *$ & $-0,04$ & $-0,01$ & $-0,01$ & $-0,02$ & 0,00 & $-0,01$ & $-0,03$ & 0,00 \\
\hline WD: Tomada de decisões & $-0,02$ & $-0,05$ & 0,00 & $-0,01$ & $-0,03$ & 0,00 & $-0,01$ & $-0,02$ & 0,01 \\
\hline WD: Significado da tarefa & $-0,01$ & $-0,04$ & 0,00 & $-0,01$ & $-0,03$ & 0,00 & $-0,02 *$ & $-0,05$ & $-0,01$ \\
\hline WD: Identificação da tarefa & $-0,02 *$ & $-0,04$ & $-0,00$ & $-0,03^{*}$ & $-0,06$ & $-0,01$ & $-0,02 *$ & $-0,05$ & $-0,01$ \\
\hline WD: Feedback do trabalho & $-0,02 *$ & $-0,05$ & $-0,00$ & $-0,02^{*}$ & $-0,04$ & $-0,01$ & $-0,03^{*}$ & $-0,05$ & $-0,01$ \\
\hline WD: Suporte social & $-0,01$ & $-0,04$ & 0,00 & $-0,01$ & $-0,03$ & 0,01 & $-0,02^{*}$ & $-0,05$ & $-0,00$ \\
\hline WD: Feedback dos outros & $-0,02 *$ & $-0,05$ & $-0,00$ & $-0,01^{*}$ & $-0,03$ & $-0,00$ & $-0,03^{*}$ & $-0,05$ & $-0,01$ \\
\hline
\end{tabular}

Nota. Efeito 1 - Restauro Relaxamento e ajustamento percebido no trabalho; Efeito 2 - Restauro Domínio e ajustamento percebido no trabalho; Efeito 3 - Restauro Autonomia e ajustamento percebido no trabalho. Valores apresentados do efeito indireto do modelo duplamente mediado. ${ }^{*} p<0,05$. LLCI $=$ Limite inferior do intervalo de confiança; ULCI Limite superior do intervalo de confiança. 
possibilidades de prevenir e intervir em situações de adoecimento por parte da gestão e da clínica da polícia é facilitada. Particularmente, amplia-se as possibilidades de intervenção ao se trabalhar com estratégias no nível individual, como as de restauro e de ajustamento no trabalho. Os resultados apontam na direção de se revisar fatores associados ao desajustamento dos policiais com o seu trabalho como um dos antecedentes do burnout. Há na literatura descrições sobre intervenções de prevenção e tratamento de burnout nas organizações (Ahola, Toppinen-Tanner, \& Seppänen, 2017), mas a maioria dos relatos são de áreas de saúde (e.g. Buruck, Tomaschek, \& Lütke-Lanfer, 2019; Wiederhold, Cipresso, Pizzioli, Wiederhold, \& Riva, 2018). A exceção encontrada nesse sentido é para a experiência com bombeiros em âmbito nacional (Melo \& Carlotto, 2017).

A pesquisa não é isenta de limitações. Uma delas foi a falta de adesão dos policiais à pesquisa. Embora a baixa adesão não seja algo incomum quando se trata de pesquisas transversais e de autorelato, esperava-se que a parceria com a polícia e a divulgação realizada por ela trouxesse aumento da taxa de resposta. Outro aspecto limitador que cabe ser registrado diz respeito às variáveis da pesquisa. Dentre as características do trabalho escolhidas, as estratégias mais demandantes não emergem como preditoras de burnout, o que limitou o teste do modelo. Ademais, embora as escalas apresentem bom ajuste psicométrico, a escala de restauro não havia sido previamente adaptada para a população em geral, então sabe-se que ela foi útil para esta pesquisa, mas sua extensão, ainda é limitada.

Não obstante às limitações, entende-se que esse trabalho contribuiu com o teste conceitual do modelo de burnout. Os resultados sugerem que as estratégias de restauro, mesmo relativamente diferentes do coping, tem função similar no modelo. Também apresentou antecedentes de estresse que diferem do usualmente estudados (i.e. nível de ajustamento) como um antecedente pouco conhecido, oculto, para o processo do policial e protetivos do processo de adoecimento no trabalho. Ademais, contribui com uma categoria profissional pouco estudada no Brasil e que tem sofrido forte influência de vários tipos nos últimos anos.

\section{Referências}

Appio, J., Carli, D. D. C., Fernandes, B. H. R., \& Frizon, N. N. (2019). PersonEnvironment Fit (PE Fit): Evidence from Brazil. International Scholarly and Scientific Research \& Innovation, 13(3), 271-276. https://doi.org/10.5281/ zenodo. 2643569

Ahola, K., Toppinen-Tanner, S., \& Seppänen, J. (2017). Interventions to alleviate burnout symptoms and to support return to work among employees with burnout: Systematic review and meta-analysis. Burnout Research, 4, 1-11. https://doi.org/10.1016/j.burn.2017.02.001

Ascari, R. A., Dumke, M., Dacol, P. M., Junior, S. M., De Sá, C. A., \& Lautert, L. (2016). Prevalência de risco para síndrome de burnout em policiais militares. Cogitare Enfermagem, 21(2), 1-10. Recuprado de https://revistas.ufpr.br/ cogitare/article/view/44610/28562

Baron, R. M., \& Kenny, D. A. (1986). The moderator-mediator variable distinction in social psychological research: Conceptual strategic and statistical considerations. Journal of Personality \& Social Psychology, 51(6) 11731182.

Borges-Andrade, J. E., Peixoto, A. L. A., Queiroga, F., \& Pérez-Nebra, A. R. (2019). Adaptation of the work design questionnaire to Brazil. Revista Psicologia Organizações e Trabalho, 19(3), 720-731. https://doi.org/10.17652/ rpot/2019.3.16837

Buruck, G., Tomaschek, A., \& Lütke-Lanfer, S. S. (2019). Burnout prevention team-process evaluation of an organizational health intervention. Journal of Public Health (Germany), 27(6), 743-754. https://doi.org/10.1007/s10389018-0999-0

Cable, D. M., \& DeRue, D. S. (2002). The convergent and discriminant validity of subjective fit perceptions. Journal of applied psychology, 87(5), 875-884. https:// doi.org/10.1037/0021-9010.87.5.875

Ceribeli, H. B., \& Severgnini, F. R. (2018). Uma análise da relação entre identificação organizacional e exaustão do trabalhador. Perspectivas Contemporâneas, 13(2), 130-150.
Chirico, F. (2016). Job stress models for predicting burnout syndrome: a review. Ann. Ist. Super. Sanita 52, 443-456. https://doi.org/10.4415/ ANN $16 \quad 03 \quad 17$

Demerouti, E. (1999). Burnout: Eine folge konkreter Abeitsbedingungen bei Dienstleistungs und Produktionstdtigkeiten. Peter Lang.

Demerouti, E., Bakker, A. B., Vardakou, I., \& Kantas, A. (2003). The convergent validity of two Burnout instruments - A multitrait-multimethod analysis. European Journal of Psychological Assessment, 19(1),12-23. https://doi. org/10.1027/1015-5759.19.1.12

Demerouti, E.; Backer, A. B.; Nachreineir, F. \& Shaufeli, W. B. (2001). The job demands-resouces model of burnout. Journal of Applied Psychology, 86(3), 499-512. https://doi.org/10.1037/0021-9010.86.3.499

De Francisco, C., Arce, C., Vílchez, M. P., \& Vales, Á. (2016). Antecedents and consequences of burnout in athletes: Perceived stress and depression. International Journal of Clinical and Health Psychology, 16(3), 239-246. https:// doi.org/10.1016/j.ijchp.2016.04.001

Edwards, J. R., Cable, D. M., Williamson, I. O., Lambert, L. S., \& Shipp, A. J. (2006). The phenomenology of fit: Linking the person and environment to the subjective experience of person-environment fit. Journal of Applied Psychology, 91(4), 802-827. https://doi.org/10.1037/0021-9010.91.4.802

Freitas, A. K. B. D. (2013). Estresse, coping e sindrome de burnout em policiais rodoviários federais (Dissertação não publicada). Universidade Federal de Santa Maria, Brasil.

González-Romá, V., \& Hernández, A. (2017). Multilevel Modeling: ResearchBased Lessons for Substantive Researchers. Annual Review of Organizational Psychology and Organizational Behavior, 4(1), 183-210. https://doi. org/10.1146/annurev-orgpsych-041015-062407

Hayes, A. F. (2013). Introduction to mediation, moderation, and conditional process analysis: A regression-based approach. New York \& London: Guilford Press.

Halbesleben, J. R. B., \& Demerouti, E. (2005). The construct validity of an alternative measure of Burnout: Investigating the English translation of the Oldenburg Burnout Inventory. Work and Stress, 19(3), 208-220. https://doi. org $/ 10.1080 / 02678370500340728$

Hidalgo Jiménez, E. M. (2019). Diseño del trabajo y burnout: un estudio de su relación. Revista Psicologia: Organizações e Trabalho, 19(4), 744-754. https://doi. org/10.17652/rpot/2019.4.17502

Hyeda, A., \& Handar, Z. (2011). Avaliação da produtividade na síndrome de Burnout. Revista Brasileira de Medicina do Trabalbo, 9(2), 78-84.

Kinnunen, U., Feldt, T., Siltaloppi, M., \& Sonnentag, S. (2011). Job demandsresources model in the context of recovery: Testing recovery experiences as mediators. European Journal of Work and Organizational Psychology, 20(6), 805-832. https://doi.org/10.1080/1359432X.2010.524411

Kristof-Brown, A. L., \& Guay, R. P. (2011). Person-environment fit. Em APA Handbook of Industrial and Organizational Psychology (Vol. 3. Maintaining, expanding, and contracting, pp. 3-50). American Psychological Association. https://doi.org/10.1037/12171-001

Lazarus, R., \& Folkman, S. (1984). Stress, appraisal, and coping. Springer.

Leite, N. M. B. (2007). Síndrome de Burnout e relacões sociais no trabalho: um estudo com professores da educação básica (Dissertação não publicada). Universidade de Brasília, Brasil.

Loo, R. (1994). Burnout among Canadian police managers. The International Journal of Organizational Analysis, 2(4), 406-417. https://doi.org/10.1108/eb028818

Luís, F. F. (2011). Burnout e bem-estar no trabalho: Estudo exploratório na Divisão da Polícia de Segurança Pública de Portimão (Dissertação não publicada). Universidade do Algarve, Faro.

Manzano-García, G., Ayala-Calvo, J. C., \& Desrumaux, P. (2021). Entrepreneurs' capacity for mentalizing: Its influence on burnout syndrome. International Journal of Environmental Research and Public Health, 18(1), 1-11. https://doi. org/10.3390/ijerph18010003

Maslach C. (1982). Burnout. The cost of caring. Englewood Cliffs, New Jersey: Prentice-Hall

Maslach, C., Jackson, S. E., Leiter, M. P., Schaufeli, W. B., \& Schwab, R. L. (1986). Maslach burnout inventory, 21, 3463-3464. Palo Alto, CA: Consulting psychologists press.

Maslach, C., \& Schaufeli, W. (1993). Historical and conceptual development of burnout. Em W. Schaufeli, C. Maslach, \& T. Marek (Eds), Professional burnout. Recent developments in theory and research (pp. 1-16). Washington, DC: Taylor \& Francis.

Maslach, C., \& Leiter, M. P. (2015). Editorial - It's time to taken action on burnout. Burnout Research, 1, 1-2.

Maslach, C., Schaufeli, W. B., \& Leiter, M. P. (2001). Job burnout. Annual Review of Psychology, 52(1), 397-422. https://doi.org/10.1146/annurev.psych.52.1.397

Melo, P. De, \& Carlotto, M. S. (2017). Programa de prevenção para manejo de estresse e Síndrome de Burnout para bombeiros: Relato de experiência de uma intervenção. Estudos de Psicologia, 22(1), 99-108. https://doi. org/10.22491/1678-4669.20170011

Menegali, T. T., Camargo, R. P. M., Rogerio, L. P. W., Carvalho, D. C., \& Magajewski, F. R. (2010). Avaliação da síndrome de burnout em policiais civis do município de Tubarão (SC). Revista Brasileira de Medicina do Trabalho, $8(2), 77-81$. 
Merino-Tejedor, E., Hontangas, P. M., \& Boada-Grau, J. (2017). The assessment of detachment among university students: Validation of the Recovery Experience Questionnaire in educational contexts. Anales de Psicologia, 33(2), 342. https://doi.org/10.6018/analesps.33.2.249811

Michinov, N. (2005). Social comparison, perceived control, and occupational burnout. Applied Psychology, 54(1), 99-118. https://doi.org/10.1111/i.14640597.2005.00198.x

Minayo, M. C. D. S., Souza, E. R. D., \& Constantino, P. (2008). Missão prevenir e proteger: condições de vida, trabalho e saúde dos policiais militares do Rio de Janeiro. Rio de Janeiro: Editora Fiocruz.

Morgeson, F. P., \& Humphrey, S. E. (2006). The Work Design Questionnaire (WDQ): Developing and validating a comprehensive measure for assessing job design and the nature of work. Journal of Applied Psychology, 91(6), 1321-1339. https://doi.org/10.1037/0021-9010.91.6.1321

Organização Mundial de Saúde (2019). Reportagem da OMS cid: burnout é um fenômeno ocupacional. Recuperado de https://www.paho.org/bra/index.php? option $=$ comcontent\&view $=$ article $\&$ id $=5949$ : cid-burnout-e-um-fenomenoocupacional\&Itemid $=875$

Parker, S. K., Morgeson, F. P., \& Johns, G. (2017). One Hundred Years of Work Design Research: Looking Back and Looking Forward. Journal of Applied Psychology, 102(3), 403-420. https://doi.org/10.1037/apl0000106

Pérez-Nebra, A. R., Pedersoli, M., Rodrigues, A., Rodrigues, C. M. L., \& Queiroga, F. (2021). Evidence of validity of the Brazilian-Portuguese Recovery Exerpeicen Questionnaire. Working paper. Universidade de Brasília.

Pienaar, J., \& Rothmann, S. (2006). Occupational stress in the South African police service. SA Journal of Industrial Psychology, 32(3), 72-78. https://doi. org/10.4102/sajip.v32i3.439

Pines, A., \& Keinan, G. (2005). Stress and burnout: the significant difference. Personality Individual Differences, 39, 625-35.

Queirós, C., Passos, F., Bártolo, A., Marques, A. J., da Silva, C. F., \& Pereira, A. (2020). Burnout and Stress Measurement in Police Officers: Literature Review and a Study With the Operational Police Stress Questionnaire. Frontiers in Psychology, 11(May), 1-23. https://doi.org/10.3389/ fpsyg.2020.00587

Sanz-Vergel, A. I., Sebastián, J., Rodríguez-Muñoz, A., Garrosa, E., MorenoJiménez, B., \& Sonnentag, S. (2010). Adaptation of the «recovery experience questionnaire» in a Spanish sample. Psicothema, 22(4), 990-996. https://doi. org $/ 10.1037 / \mathrm{t} 03569-000$

Schaufeli, W. B. (2017). Applying the Job Demands-Resources model: A how to' guide to measuring and tackling work engagement and burnout. Organizational Dynamics, 46(2), 120-132. https://doi.org/10.1016/j. orgdyn.2017.04.008

Schuster, M. D. S., \& Dias, V. D. V. (2018). Oldenburg Burnout Inventoryvalidação de uma nova forma de mensurar Burnout no Brasil. Ciência \& Saúde Coletiva, 23, 553-562. https://doi.org/10.1590/1413$\underline{81232018232.27952015}$

Shimazu, A., Sonnentag, S., Kubota, K., \& Kawakami, N. (2012). Validation of the Japanese version of the recovery experience questionnaire. Journal of Occupational Health, 54(3), 196-205. https://doi.org/10.1539/joh.11-0220$\underline{\mathrm{OA}}$

Silva, L. P. D. (2012). Organizaçãa do trabalho e vivências de prazer e sofrimento no trabalho em delegacias de polícia do Distrito Federal (Monografia de especialização não publicada). Universidade de Brasília, Brasília.

Silva, C. C. S., Santos, G. M. dos, Amorim, M. dos S., Costa, M. do M. H., \& Medeiros, S. M. de. (2018). A síndrome de burnout entre policiais civis. Reme Revista Mineira de Enfermagem, 22, 1-7. https://doi.org/10.5935/1415$\underline{2762.20180025}$

Silveira, N. D. M., Vasconcellos, S. J. L., Cruz, L. P., Kiles, R. F., Silva, T. P., Castilhos, D. G., \& Gauer, G. J. C. (2005). Assessment of burnout levels in a sample of police officers. Revista de Psiquiatria do Rio Grande do Sul, 27(2), 159-163.

Sonnentag, S., \& Fritz, C. (2007). The Recovery Experience Questionnaire: development and validation of a measure for assessing recuperation and unwinding from work. Journal of Occupational Health Psychology, 12(3), 204-221. https://doi.org/10.1037/1076-8998.12.3.204

Sonnentag, S. (2018). The recovery paradox: Portraying the complex interplay between job stressors, lack of recovery, and poor well-being. Research in Organizational Behavior, 38, 169-185. https://doi.org/10.1016/j. riob.2018.11.002

Tamayo, Á. (2002). Exaustão emocional no trabalho. Revista de Administração da Universidade de São Paulo, 37(2), 26-37.

Tamayo, R. M., Mendonça, H., \& Silva, E. D. (2012). Relação entre estresse ocupacional, coping e Burnout. Em M. C. Ferreira \& H. Mendonça (Orgs.), Saúde e bem-estar no trabalbo: dimensões individuais e culturais,(pp. 35-57). São Paulo: Casa do Psicólogo.

Vazquez, A. C. S., Santos, A. S., Costa, P. V., Freitas, C. P. P. Witte, H., \& Schaufeli, W. B. (2019). Trabalho e Bem-Estar: Evidências da Relação entre Burnout e Satisfação de Vida. Avaliação Psicológica, 18(51), 372-381. https:// doi.org/10.15689/ap.2019.1804.18917.05
Werbel, J., \& Demarie, S. M. (2001). Aligning strategic human resource management and person-environment fit: A strategic contingency perspective. Academy of Management Proceedings \& Member Directory, G1-G6. https://doi.org/10.1016/i. hrmr.2005.10.001

Wiederhold, B. K., Cipresso, P., Pizzioli, D., Wiederhold, M., \& Riva, G. (2018). Intervention for physician burnout: A systematic review. Open Medicine (Poland), 13(1), 253-263. https://doi.org/10.1515/med-2018-0039

\section{Informações sobre os autores:}

\section{Paula Soares Lira}

Av. Maria de Melo Q2, LT, perimetral Norte, setor empresarial 74583-285 Goiânia, GO, Brasil

E-mail: paulaslirac@gmail.com

\section{Amalia Raquel Pérez-Nebra}

E-mail: amalia.perez@unb.br

Fabiana Queiroga

E-mail: fabiana.queiroga@univ-cotedazur.fr 